\title{
Pelvic lymph nodes: distribution and nodal tumour burden of urothelial bladder cancer
}

\author{
Roland Seiler, ${ }^{1}$ Michael von Gunten, ${ }^{1}$ George N Thalmann, ${ }^{2}$ Achim Fleischmann ${ }^{1}$
}

${ }^{1}$ Department of Pathology, University of Bern, Switzerland ${ }^{2}$ Department of Urology, University of Bern, Switzerland

\section{Correspondence to}

Achim Fleischmann, Consultant, Department of Pathology,

Murtenstrasse, CH-3010 Bern Switzerland; achim. fleischmann@pathology.unibe. ch

Accepted 28 January 2010 Published Online First 3 April 2010

\section{(2) UNLOCKED}

This paper is freely available online under the BMJ Journals unlocked scheme, see http:// jcp.bmi.com/site/about/ unlocked.xhtml

\section{ABSTRACT}

Aims To evaluate the number of lymph nodes and the lymph node tumour burden in different anatomical pelvic regions to better asses the impact of variations in the extent of lymphadenectomy on reported LN parameters and pelvic tumour clearance.

Methods 162 patients with lymph-node-positive urothelial carcinoma of the bladder were treated by cystectomy and extended pelvic lymphadenectomy. Various lymph node parameters were determined separately for the three pelvic regions (external iliac, obturator and internal iliac).

Results 0 f 4080 evaluated lymph nodes (median 25 per patient, range $8-55) 39 \%, 35 \%$ and $26 \%(p<0.05)$ were found in the external iliac, obturator and internal iliac region, respectively. The distribution of the 625 lymph node metastases (median two per patient, range 1-35) was not significantly different between the regions (external iliac 33\%, obturator 38\%, internal iliac 29\%). However, the median diameter of largest metastasis and total diameter of all metastases were smallest in the internal iliac region (external iliac $0.85 \mathrm{~cm}, 1.1 \mathrm{~cm}$; obturator $0.8 \mathrm{~cm}, 1.0 \mathrm{~cm}$; internal iliac $0.6 \mathrm{~cm}, 0.8 \mathrm{~cm}$; $\mathrm{p}<0.03, \mathrm{p}<0.05$; for median diameter of largest metastasis and total diameter of all metastases, respectively). Metastases in only one region were found in $33 \%$ of patients (external iliac $13 \%$, obturator $10 \%$, internal iliac 10\%); these three groups showed no significant difference in survival. No difference was detected in lymph node parameters between genders.

Conclusions Lymph node counts and retrieval of metastases depends on the extent of pelvic lymphadenectomy. Dissection not including the internal iliac region misses $26 \%$ of all pelvic lymph nodes, $29 \%$ of metastases, and understages a substantial number of patients as pNO $(10 \%)$.

\section{INTRODUCTION}

Up to $27 \%$ of surgically treated bladder cancer patients are found to have lymph node metastasis upon histological examination when an extended pelvic lymphadenectomy is performed. ${ }^{1-3}$ However, no consensus exists about the recommended surgical field of pelvic lymph node dissection, ${ }^{245}$ particularly about dissection of the internal iliac region.

In anatomical studies, approximately 20 lymph nodes may be routinely found in the pelvis. ${ }^{6}$ The distribution of pelvic lymph node metastases from bladder cancers in different pelvic regions has previously been investigated in $81^{2}$ and in $48^{1}$ patients, respectively. Lymph node tumour burden was reported as the number of positive nodes; however, other parameters of metastases such as the largest diameter and total diameter were not. In this study, we determined these parameters in a single institution cohort of 162 patients with urothelial carcinoma of the bladder undergoing cystectomy and extended pelvic lymphadenectomy. The routine submission of the lymphadenectomy specimens from six pelvic regions (bilateral three regions) provides individual data from every region (external iliac, obturator and internal iliac).

Different series $^{7-9}$ of gender-specific pelvic cancers suggest a higher lymph node count in women than in men. Here, we analyse lymph node counts and characteristics of lymph node metastases in women and men undergoing standardised surgery for the same disease.

\section{MATERIAL AND METHODS \\ Patients}

A standardised extended bilateral pelvic lymphadenectomy with cystectomy was performed in 840 patients with invasive bladder cancer between January 1985 and April 2008 at the Department of Urology, University of Bern. None of the patients received neoadjuvant therapy. One hundred and sixty-two (30 women, 132 men) of these patients with urothelial cancer of the bladder and without preoperative clinical evidence of metastases (physical examination, chest $\mathrm{x}$-ray, bone scan, intravenous urography, and CT scan of the pelvis when it became available) had lymph node metastases upon pathological examination. All patients were followed prospectively.

\section{Surgical technique}

Bilateral pelvic lymphadenectomy was performed in all patients according to a standard protocol described previously by Mills. ${ }^{10}$ In short, all lymphatic and connective tissue was meticulously removed from the common iliac bifurcation along the external iliac vessels to the inguinal ligament. Anterolateral limits were the external iliac artery and the genitofemoral nerve (external iliac region). The obturator fossa was completely cleared of all tissue other than the obturator nerve (obturator region). The ventral aspect of the internal iliac vein as well as the internal iliac artery and branches were freed of all lymphatic and connective tissue (internal iliac region). The resected tissue of the six regions was sent separately in formalin for histological examination. The cystectomy protocol has previously been described in detail. ${ }^{11}$

\section{Pathology}

The cystectomy and lymph node specimens were examined by pathologists experienced in genitourinary pathology at the Institute of Pathology, 
University of Bern. All slides were reviewed by two pathologists (AF and $\mathrm{MvG}$ ).

The cystectomy and lymphadenectomy specimens were analysed according to a standard protocol described earlier. ${ }^{5}$ Tumour type, tumour stage, tumour grade and the presence of carcinoma in situ were histologically determined. All tumours were classified according to the sixth International Union Against Cancer (UICC) classification of 2002. ${ }^{12}$ For each pelvic region, the total number of histologically confirmed lymph nodes as well as the number and diameter of lymph node metastases (figure 1) were recorded.

\section{Statistical analysis}

Lymph node data for the three bilateral pelvic regions and results stratified for gender were compared using a two-sided Wilcoxon rank-sum test. Differences in outcome events between subgroups were analysed using a two-sided Fisher test. All analyses were performed using $\mathrm{R}$ software package, version 2.9.1.

\section{RESULTS}

\section{Characteristics of patients, cystectomy and lymphadenectomy specimens}

Median age of the 162 lymph node positive patients (30 females, 132 males) at surgery was 67 years (range, 35-89 years; table 1 ). In general, patients had grade 3 tumours $(n=157)$, and grade 2 tumours $(n=5)$ were observed rarely. Most patients presented with advanced primary tumours (pT3/4; $n=139$ ) and advanced lymph node involvement $(\mathrm{pN} 2 ; \mathrm{n}=110)$. A median of 25 lymph nodes (range 8-55) and two metastases (range 1-35) per patient were identified in the three bilateral regions. Median follow-up of the cohort was 7.1 years; 96 patients relapsed, 115 died, and 88 died due to progressive disease. Survival was significantly different between $\mathrm{pN} 1$ and $\mathrm{pN} 2$ subgroups $(p<0.05$, table 2$)$. No difference was observed between patients grouped according to isolated metastases in one of the three pelvic regions.

\section{Distribution of all lymph nodes in the three pelvic regions}

In total, 4080 lymph nodes were detected in the three regions (table 3). Most of the lymph nodes recovered were in the external iliac $(n=1599 ; 39 \%)$ and obturator region $(n=1438$;

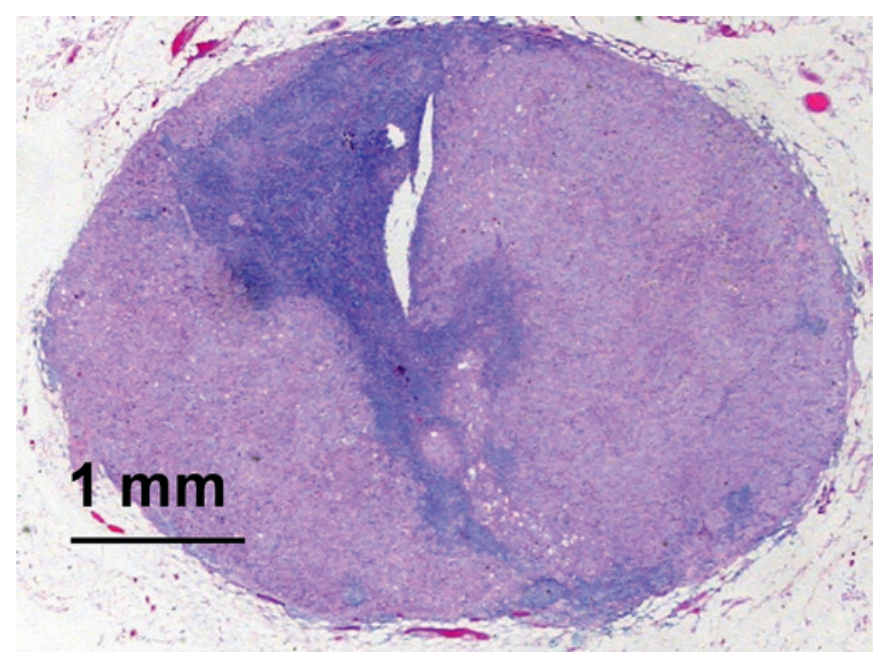

Figure 1 Lymph node metastasis of urothelial bladder cancer. The largest diameter of all metastases was measured on slides.
Table 1 Clinicopathological data of 162 nodal positive bladder cancer patients

\begin{tabular}{|c|c|}
\hline Patient data & \\
\hline Age (years) at surgery, median (range) & $67(35-89)$ \\
\hline Female/male, $\mathrm{n}$ & $30 / 132$ \\
\hline \multicolumn{2}{|l|}{ Cystectomy data: stage, $\mathrm{n}$} \\
\hline pT1 & 5 \\
\hline pT2 & 18 \\
\hline рТ3а & 35 \\
\hline pT3b & 62 \\
\hline pT4 & 42 \\
\hline \multicolumn{2}{|l|}{ Lymphadenectomy data* } \\
\hline Total no. of evaluated nodes, $n$ & 4080 \\
\hline No. of evaluated nodes per patient, median (range) & $25(8-55)$ \\
\hline No. of positive nodes per patient, median (range) & $2(1-35)$ \\
\hline \multicolumn{2}{|l|}{ Lymph node stage, $\mathrm{n}$} \\
\hline pN1 & 52 \\
\hline pN2 & 110 \\
\hline Diameter $(\mathrm{cm})$ of largest metastasis per patient, median (range) & $1.0(0.1-4.9)$ \\
\hline Total diameter $(\mathrm{cm})$ of metastases per patient, median (range) & $1.4(0.1-39.9)$ \\
\hline
\end{tabular}

$35 \%)$. Significantly fewer nodes were dissected in the internal iliac region $(n=1043 ; 26 \% ; p<0.005)$.

\section{Frequency of lymph node metastases}

Metastases were found in 625 lymph nodes (table 3). Their distribution in the external iliac, obturator and internal iliac region was $33 \%$, 38\% and $29 \%$, respectively ( $p>0.05$ ). Metastases in only one region were found in $33 \%$ of patients (external iliac, obturator and internal iliac region in $13 \%, 10 \%$ and $10 \%$ of the patients, respectively); $50 \%$ of all patients had lymph node metastases in the internal iliac region.

\section{Lymph node tumour burden in the three pelvic regions}

Median diameter of the largest metastasis per patient and median total diameter of all metastases per patient were similar in the external iliac $(0.85 \mathrm{~cm}, 1.1 \mathrm{~cm})$ and obturator region $(0.8 \mathrm{~cm}, 1.0 \mathrm{~cm})$, respectively (table 3$)$. In the internal iliac region, median diameter of the largest metastasis was significantly lower than in the other two regions $(0.6 \mathrm{~cm} ; \mathrm{p}<0.03)$, and median total diameter of all metastases was only significantly lower compared with the external iliac region $(0.8 \mathrm{~cm}$; $\mathrm{p}<0.05)$.

Table 2 Survival data of the cohort

\begin{tabular}{|c|c|c|c|c|}
\hline & $\begin{array}{l}\text { Death from } \\
\text { bladder cancer }\end{array}$ & p Value & $\begin{array}{l}\text { Recurrent } \\
\text { cancer }\end{array}$ & p Value \\
\hline \multicolumn{5}{|c|}{ Lymph node tumour burden } \\
\hline \multicolumn{5}{|c|}{ Lymph node stage, n (\%) } \\
\hline pN1 & $20 / 52(38)$ & $<0.004$ & $24 / 52(46)$ & $<0.004$ \\
\hline $\mathrm{pN2}$ & $68 / 107(62)$ & & $77 / 110(70)$ & \\
\hline \multicolumn{5}{|c|}{ Diameter of largest metastasis, n (\%) } \\
\hline$<$ Median & $40 / 79(51)$ & 0.3 & $45 / 80(56)$ & 0.1 \\
\hline$\geq$ Median & $48 / 80(60)$ & & $56 / 82(68)$ & \\
\hline \multicolumn{5}{|c|}{ Total diameter of metastases, n (\%) } \\
\hline$<$ Median & $36 / 77(47)$ & $<0.04$ & $42 / 79(53)$ & $<0.04$ \\
\hline$\geq$ Median & $52 / 82(63)$ & & $59 / 83(71)$ & \\
\hline \multicolumn{5}{|c|}{ Pelvic region if isolated metastases, $\mathrm{n}(\%)$} \\
\hline External iliac & $9 / 21(43)$ & 1.00 & $11 / 21(52)$ & 1.00 \\
\hline Obturator & $8 / 17(47)$ & & $9 / 17(53)$ & \\
\hline Internal iliac & $7 / 15(41)$ & & $9 / 17(53)$ & \\
\hline
\end{tabular}


Table 3 Lymph node data evaluated for the three pelvic regions

\begin{tabular}{|c|c|c|c|}
\hline & External iliac region & Obturator region & Internal iliac region \\
\hline \multicolumn{4}{|l|}{ Removed lymph nodes } \\
\hline Total no. of lymph nodes, (\%) & 1599 (39) & $1438(35)$ & $1043(26)^{*}$ \\
\hline $\begin{array}{l}\text { Median no. of lymph nodes per patient, } \\
\text { (range) }\end{array}$ & $8(0-43)$ & $8(0-34)$ & $6(0-18)$ \\
\hline \multicolumn{4}{|l|}{ Lymph node metastases } \\
\hline Total no. of metastases, (\%) & $204(33)$ & $238(38)$ & $183(29) \dagger$ \\
\hline $\begin{array}{l}\text { Median no. of metastases per patient, } \\
\text { (mean) }\end{array}$ & $1(2.3)$ & $2(2.8)$ & $1(2.3)$ \\
\hline $\begin{array}{l}\text { Median diameter }(\mathrm{cm}) \text { of largest } \\
\text { metastasis per patient }\end{array}$ & 0.85 & 0.8 & $0.6 \neq$ \\
\hline $\begin{array}{l}\text { Median total diameter }(\mathrm{cm}) \text { of all } \\
\text { metastases per patient }\end{array}$ & 1.1 & 1.0 & $0.8 \S$ \\
\hline $\begin{array}{l}\text { Total diameter }(\mathrm{cm}) \text { of all metastases } \\
\text { per region, }(\%)\end{array}$ & $193(40)$ & $191(39)$ & $100(21)$ \\
\hline \multicolumn{4}{|c|}{$\begin{array}{l}\text { Most lymph nodes were detected in the external iliac region; lymph node tumour burden was lowest in the internal iliac region. } \\
{ }^{*} p<0.0001 \text { (internal versus external; internal versus obturator). } \\
\dagger 17 \text { patients with pelvic lymph node metastases solely in the internal iliac region. } \\
\neq p<0.03 \text { (internal versus external; internal versus obturator). } \\
\S p<0.05 \text { (internal versus external). }\end{array}$} \\
\hline
\end{tabular}

\section{Lymph node counts and nodal tumour burden stratified for gender}

Lymph node distribution in the three pelvic regions, and the frequency, distribution or diameter of metastases, were not significantly different between women and men (table 4).

\section{DISCUSSION}

Differences in the surgical protocols for pelvic lymph node dissection might influence lymph node counts in lymphadenectomy specimens and tumour clearance in the pelvis. ${ }^{4}$ In particular, the clearance of lymph nodes from the internal iliac region is controversial. Our single institution series of patients treated uniformly by cystectomy and bilateral extended pelvic lymph node dissection for urothelial cancer of the bladder allows us to describe pelvic lymph node distribution and to quantify nodal tumour burden, reflected by number of positive nodes, diameter of largest metastasis and total diameter of all metastases.

In line with Leissner et $a l^{2}$ and Abol-Enein et al ${ }^{1}$ a median of 25 pelvic lymph nodes per patient were dissected. Similar proportions of lymph nodes were found in the external iliac (39\%) and obturator region (35\%), and $26 \%$ of all nodes were present in the internal iliac region. Consequently, a limited pelvic lymphadenectomy without dissection of the internal iliac region could potentially miss one in four lymph nodes, resulting in less accurate staging.

Lymph node tumour burden, reflected by number of positive lymph nodes, was not significantly different between the three pelvic regions. The external iliac, obturator and internal iliac region harboured $33 \%, 38 \%$ and $29 \%$ of all pelvic lymph node metastases, respectively. These findings are in accordance with the only other study evaluating such distribution. ${ }^{2}$ However, the median diameter of the largest metastasis and median total diameter of all metastases per patient were substantially smaller in the internal iliac region $(0.6 \mathrm{~cm}, 0.8 \mathrm{~cm})$ when compared with the external iliac $(0.85 \mathrm{~cm}, 1.1 \mathrm{~cm})$ and the obturator $(0.8 \mathrm{~cm}$, $1.0 \mathrm{~cm}$ ) region. Importantly, $50 \%$ of all patients had lymph node metastases in the internal iliac region comprising $10 \%$ with isolated metastases. Consequently, a limited pelvic lymphadenectomy not including the internal iliac region would incompletely remove pelvic lymph node metastases in half of the nodal-positive patients with bladder cancer. This is of high clinical relevance, since up to $30 \%$ of these patients can be cured by cystectomy and extended lymphadenectomy. ${ }^{35}$

Recent series on gender-specific pelvic cancers suggest differences in pelvic lymph node counts between women (median, $25-38)^{7-9}$ and men (median, 8-22)..$^{513-15}$ Data on numbers of negative and positive pelvic lymph nodes in a mixed cohort treated for the same cancer are missing. We could not detect differences in lymph node counts or nodal tumour burden between the genders. Therefore, the above-mentioned differences might primarily indicate variations in the surgical procedure.

In conclusion, pathologists and urologists should realise that retrieval of pelvic lymph nodes and metastases largely depends on the extent of lymphadenectomy. Excluding the internal iliac region from pelvic lymphadenectomy is associated with incomplete clearance of positive lymph nodes in $50 \%$ of the node positive patients, leaves approximately $29 \%$ of all lymph node metastases in situ, and understages $10 \%$ of the patients as pN0. In this cohort, no difference in lymph node parameters was detected between women and men.

Table 4 Analysis of pelvic lymph nodes and characteristics of metastases stratified by gender and pelvic regions did not yield significant differences

\begin{tabular}{|c|c|c|c|c|c|c|}
\hline & \multicolumn{2}{|c|}{ External iliac region } & \multicolumn{2}{|l|}{ Obturator region } & \multicolumn{2}{|c|}{ Internal iliac region } \\
\hline & Women & Men & Women & Men & Women & Men \\
\hline Median no. of nodes, (per patient range) & $8(0-40)$ & $8.5(0-43)$ & $10.5(0-34)$ & $8(0-30)$ & $5(0-15)$ & $6(0-18)$ \\
\hline $\begin{array}{l}\text { Median no. of metastases, (per patient } \\
\text { range) }\end{array}$ & $2(1-4)$ & $1(1-9)$ & $2(1-10)$ & $1(1-23)$ & $1(1-6)$ & $1(1-13)$ \\
\hline $\begin{array}{l}\text { Median diameter }(\mathrm{cm}) \text { of largest } \\
\text { metastasis, (per patient range) }\end{array}$ & $0.6(0.1-4.0)$ & $1.0(0.1-4.9)$ & $0.8(0.1-4.9)$ & $0.8(0.1-4.9)$ & $0.6(0.1-1.2)$ & $0.6(0.1-4.9)$ \\
\hline $\begin{array}{l}\text { Median total diameter }(\mathrm{cm}) \text { of all } \\
\text { metastases, (per patient range) }\end{array}$ & $0.8(0.1-7.0)$ & $1.58(0.1-10.5)$ & $0.9(0.1-14.2)$ & $1.1(0.1-22.9)$ & $0.7(0.1-3.1)$ & $0.8(0.1-7.9)$ \\
\hline
\end{tabular}




\section{Take-home messages}

- The surgical field of lymphadenectomy in urothelial cancer of the bladder is controversial, particularly the dissection of the internal iliac region.

- Limited lymphadenectomy not comprising the internal iliac region: (1) is associated with incomplete clearance of positive lymph nodes in $50 \%$ of the lymph node positive patients, (2) leaves approximately $29 \%$ of all pelvic lymph node metastases in situ, (3) understages $10 \%$ of the patients as pNO.

\section{Competing interests None.}

Provenance and peer review Not commissioned; externally peer reviewed.

\section{REFERENCES}

1. Abol-Enein $\mathbf{H}$, El-Baz M, Abd El-Hameed MA, et al. Lymph node involvement in patients with bladder cancer treated with radical cystectomy: a patho-anatomical study-a single center experience. J Urol 2004;172:1818-21.

2. Leissner J, Ghoneim MA, Abol-Enein $\mathrm{H}$, et al. Extended radical lymphadenectomy in patients with urothelial bladder cancer: results of a prospective multicenter study. $J$ Urol 2004;171:139-44.

3. Stein JP, Lieskovsky G, Cote R, et al. Radical cystectomy in the treatment of invasive bladder cancer: long-term results in 1,054 patients. J Clin Oncol 2001:19:666-75.
4. Dhar NB, Klein EA, Reuther AM, et al. Outcome after radical cystectomy with limited or extended pelvic lymph node dissection. J Urol 2008;179 873-8.

5. Fleischmann A, Thalmann GN, Markwalder R, et al. Extracapsular extension of pelvic lymph node metastases from urothelial carcinoma of the bladder is an independent prognostic factor. J Clin Oncol 2005:23. 2358-65.

6. Weingartner K, Ramaswamy A, Bittinger A, et al. Anatomical basis for pelvic lymphadenectomy in prostate cancer: results of an autopsy study and implications for the clinic. J Urol 1996;156:1969-71.

7. Angioli R, Plotti F, Palaia I, et al. Update on lymphadenectomy in early and advanced ovarian cancer. Curr Opin Obstet Gynecol 2008;20:34-9.

8. Panici PB, Scambia G, Baiocchi G, et al. Anatomical study of para-aortic and pelvic lymph nodes in gynecologic malignancies. Obstet Gynecol 1992;79: 498-502.

9. Possover M, Krause N, Plaul K, et al. Laparoscopic para-aortic and pelvic lymphadenectomy: experience with 150 patients and review of the literature. Gynecol Oncol 1998;71:19-28.

10. Mills RD, Turner WH, Fleischmann A, et al. Pelvic lymph node metastases from bladder cancer: outcome in 83 patients after radical cystectomy and pelvic lymphadenectomy. J Urol 2001;166:19-23.

11. Studer UE, Danuser H, Merz VW, et al. Experience in 100 patients with an ileal low pressure bladder substitute combined with an afferent tubular isoperistaltic segment. J Urol 1995;154:49-56.

12. Sobin LH, Wittekind C, eds. TNM atlas. 6th edn. New York: Wiley-Liss, 2002

13. Inman BA, DiMarco DS, Slezak JM, et al. Outcomes of Gleason score 10 prostate carcinoma treated by radical prostatectomy. Urology 2006;68:604-8.

14. Palapattu GS, Allaf ME, Trock BJ, et al. Prostate specific antigen progression in men with lymph node metastases following radical prostatectomy: results of long-term follow-up. J Urol 2004;172:1860-4.

15. Thurairaja R, Studer UE, Burkhard FC. Indications, extent, and benefits of pelvic lymph node dissection for patients with bladder and prostate cancer. Oncologist 2009:14:40-51. 